\title{
NOTA SOBRE HERMENÊUTICA: A LINGUAGEM ENTRE O SUJEITO E O OBJETO
}

Marcia Tiburi

SÍNTESE - A hermenêutica pode ser vista como uma teoria do conhecimento não subjetivista, voltada para a experiência do estranho e neste sentido capaz de assegurar um lugar que salvaguarde a dignidade do objeto no processo do conhecimento. A preocupação com o espaço do objeto reside na necessidade de ponderar uma questão que não é apenas gnosiológica, mas, inclusive, ética.

PALAVRAS-CHAVE - Hermenêutica. Linguagem. Sujeito. Objeto.
ABSTRACT - The Hermeneutic can be considered one non-subjectvistic knowledge's theory, tumed toward the experience of strange, and, in this sense, able to assure one place that preserve the dignity of object in the knowledge's process. The preoccupation with the space of object is in the necessity to cogitate one question that not is only gnosiological, but etical.

KEY WORDS - Hermeneutic. Language. Subject. Object.

O objetivo deste texto é perscrutar a posição da questão hermenêutica no que se refere à relação entre sujeito e objeto, ponto básico da teoria do conhecimento revelado também sob a forma de uma ética e uma teoria social. Embora a filosofia dos tempos de hoje pretenda a superação de uma tal questão na perspectiva de uma filosofia da linguagem que privilegia a relação entre sujeitos na comunidade (ideal) de comunicação, o problema não se encontra superado, pois os objetos de tal modo abandonados, ou permaneceram na mesma, ou tornaram-se tanto mais apenas objetos: o que se manipula, sobre o que se decide, e nada mais. Um problema insuspeito se coloca no fato de que mesmo o que deveria ser sujeito é, às vezes, condenado a ser objeto (seres da natureza, a própria natureza, seres humanos não dotados de uma racionalidade considerada "ideal", a exemplo dos tidos como loucos, ignorantes, os que vivendo outra cultura pensam e agem de outro modo em relação aos padrões e desejos ocidentais...).

Doutoranda em Filosofia (UFRGS), Professora na Universidade do Vale do Rio dos Sinos - UNISINOS. 
A questão não é a busca de uma nova objetividade, mas a compreensão do lugar do exílio do elemento que não é sujeito, elemento negativo para o conhecimento na sua forma tradicional, e como ele pode ser, em certo sentido, ativo na formação da compreensão. Quer-se saber onde tal elemento participa do espaço de existência da hermenêutica, considerada aqui um lugar privilegiado para esta perquirição na medida em que ela abre caminho para tal consideração sobretudo na proposta gadameriana de uma fusão (que é muito mais um jogo) de horizontes e tendo em vista a afirmação de Gadamer: "a compreensão não é nunca um comportamento subjetivo no que diz respeito a um objeto dado, mas pertence à história efetual, isto é, ao ser do que se compreende". ${ }^{1}$ Ao invés de investigar a partir do ponto de vista de um autor específico, o texto pretende, a partir do sentido da própria hermenêutica instaurado historicamente, perceber uma possibilidade que parece fundamental na própria implantação de uma perspectiva hermenêutica. Considerando-se que a hermenêutica traz em seu âmago um problema gnosiológico essencial ao seu próprio sentido, o texto procura ver como ela é capaz de superar a perspectiva idealista e até que ponto pode ser observada em sua base uma posição materialista (aquela que se preocupa com a primazia do objeto no processo de conhecimento contra uma primazia do sujeito), embora os hermeneutas stricto sensu jamais tenham-na ponderado ou dela se ocupado. Trata-se de possibilitar a consideração de um elemento crítico no seio da hermenêutica no sentido de um rompimento com a tradição não apenas idealista como de toda a filosofia da subjetividade (na qual a filosofia da intersubjetividade pode se tornar). Como é peculiar à hermenêutica uma valorização da tradição, não se pretende esquecer o elemento hegeliano da negação determinada - retomado pela hermenêutica de Gadamer - na averiguação de tal possibilidade, ou seja, é preciso atentar para o estatuto especial disto que se pode chamar um rompimento.

Fica clara, a partir das premissas aqui dadas, a impossibilidade de querer inscrever este texto na análise ou como contribuição para a corrente mais formal da hermenêtica (embora isto fosse interessante), sobretudo porque a tentativa aqui é de um olhar que busca entendê-la mais como algo adjetivo, e não substantivo, como algo que faz parte de todo conhecimento possível, e não propriamente como teoria inteira.

O problema da hermenêutica é velho. Existe desde que existe a pergunta, fruto do ato humano instaurado perante a estranheza do mundo no momento simples e decisivo do que a filosofia grega chamou admiração $(\vartheta \alpha \nu \mu \alpha \zeta \in t \nu)$. Tal questão perpassa a história da filosofia desde os gregos, viaja pela Idade Média e o Renascimento, e chega ao mundo moderno resguardando um sentido que se

Gadamer, Hans-Georg. Verdad y metodo I. Fundamentos de una hermenéutica filosófica. Salamanca: Sigueme, 1996. p. 13-14. 
modifica historicamente mas não perde um caráter necessário já existente no seu instante mais primordial, num instante originário. O significado de Hp$\mu \eta \nu \in \iota \in \iota \nu$ ou declarar, anunciar, esclarecer, traduzir e, por fim, interpretar, diz respeito à necessidade de superar uma pergunta ancestral, pergunta que nasce com a própria humanidade. Esta pergunta é o sinal da sabedoria que acompanha o conceito de humanidade (assim como a razão acompanha o conceito de ser humano) e que poderia ser apenas um anacoluto ou uma interrogação ontologicamente fundada, situada ou dirigida a algo abstrato. No entanto, ela tem uma direção muito específica, sendo colocada acerca do Verbo - a um só tempo início e linguagem hipostaticamente sintetizados - e que estabelece uma cumplicidade essencial entre a compreensão do mundo e o sentimento e o sentido da religiosidade enquanto perplexidade do ser humano frente ao que ele não compreende. $\mathrm{O}$ ser humano pergunta sobre o Verbo que está no início, o que significa o mesmo que perguntar por que o ser humano é criado pela linguagem e, justamente, uma linguagem que enquanto o precede é inacessível à sua compreensão. A pergunta que dará a luz ao conhecimento já é um ato de sabedoria, porque leva adiante, transporta para outra realidade - pois apenas aí aparece o conhecimento - sendo neste momento que brota o propriamente humano. A palavra e a sabedoria coexistindo no mesmo lugar dizem o que é Deus: o que o homem não alcança, o que ele deseja e, enquanto instância de certo modo especular (pois o homem quer ser a imagem e semelhança de Deus), faz com que o homem, num sentido, crie o mundo.

A hermenêutica desde sempre se dirige ao que não é compreendido no anseio de dar-lhe uma expressão, de fazê-lo falar, mas a partir dela é possivel considerarse que há expressão e, portanto, linguagem, mesmo no abscôndito: a linguagem do que não tem linguagem. Esta a aporia na qual ela se vê envolvida. Por isso ela não deve ser entendida apenas como a compreensão do que possa ser dito, mas como o desejo de compreender o que não pode ser simplesmente dito. Eis a fala que ela deve, ou ao menos deseja, ao fundo, revelar.

Hp$\mu \epsilon \nu \in L \epsilon L \nu$, para dar uma notícia etimológica, remonta ao deus grego Hermes, mensageiro que traria aos homens a palavra divina, mediador sem o qual toda compreensão ficaria truncada ou impossivel. Ele traduziria aos seres humanos o que não lhes era dado a conhecer por caminhos evidentes. Hermes símbolo da capacidade lingüística, da capacidade de traduzir e de compreender cumpria a tarefa de conectar dois mundos. Como se no miolo da existência o ser humano só pudesse compreender a sacralidade nela viva e sua contraparte profana através de um acesso por sua vez também sagrado (não seria por isso que a linguagem que fala do sagrado tornou-se para todos os efeitos sagrada?). A questão que resta é própria da hermenêutica e também da teoria do conhecimento: qual a relação entre estes dois mundos? Como conectar espaços de realidade tão diferentes? Como, finalmente, o sujeito pode falar sobre o objeto, sobretudo quando este objeto fala por si mesmo, quando, mostrando-se e sendo oculto numa estranha concomitância, ele fala muito antes de se poder compreendê-lo? Isto leva à consideração de que uma linguagem não pode traduzir 
a verdade de outra sob pena de mentira, erro, pecado ou traição. Indo-se, porém, mais ao fundo, ver-se-á que toda linguagem incorre num destes atos de um modo ou outro. O problema não é compreender como a linguagem se instaura, mas darse conta de que ela se instaura em função de um vazio, de uma mudez que o homem não suporta, e que neste ato ela é mentira ou, mais propriamente, metáfora, como queria Nietzsche. Se a verdade não pode ser mentira ela é metáfora. ${ }^{2}$ (Resta uma questão sem resposta; ou o Verbo, a Palavra é verdade, enquanto ela é Deus, ou ela é mentira, enquanto é humana; contudo, 'Deus' não seria metáfora?)

De um lado o mundo do divino, o sagrado, de outro o mundo profano dos homens: entre eles o abismo da incomunicabilidade primeva e o desejo de ler possiveis sinais imersos no intangível. Sinais que anulariam a separação entre os mundos tornando-os um só numa benfazeja reconciliação, quando nenhuma Babel permaneceria intacta e a palavra adâmica fosse restaurada para a maior glónia de Deus e o verdadeiro compartilhar humano. Para o simples humano o acesso ao sagrado - que era também o acesso ao outro imediato, ao mistério do mundo sem mistério que é o cotidiano profano - estaria fechado, e foi apenas a dor da angústia frente ao que lhe indagava - este mesmo mundo sobre o qual ele indagava - que o levou a insistir na linguagem (embora ela promovesse também uma inevitável confusão) renascida num tempo que se perdeu, espontaneamente, na exata contramão de qualquer deliberação possível, na necessidade de ler o expresso nas linhas do cosmo sublime e assustador, na estranha natureza, no outro, pleno de significados e proibido à significação. A linguagem viria salvar a relação do ser humano com o fenômeno, na medida em que através dela uma unidade, no mínimo aparente, seria trazida à luz apesar de toda confusão. Nela, como mãe dos pensamentos, o ser humano encontraria a segurança concreta que lhe permitiria entregar-se ao mundo e, quando necessário, fugir deste mesmo mundo, pois a linguagem implicaria entrar em contato com o mistério da existência e abstrair-se ao lado ameaçador deste mistério, permitindo não se sucumbir às suas potências. A linguagem era a possibilidade do contato, mas, frẹte a isto, também um talismã ou uma forma de exorcismo, sempre com vistas à autodefesa, já que sendo humana ela obedece ao instinto de sobrevivência do qual só o não humano está liberto.

A linguagem não era mais apenas um meio de se chegar ao ponto que se encara como problema, ela mesma se tornou problema. Não era mero instrumento, pois ela mesma existia em algum lugar como substância: o Verbo do início. 0 abismo e a ponte sobre o abismo seria, ao mesmo tempo, o verbo incógnito e redentor, desde sempre eminentemente lingüístico, para o qual o homem buscava

Nietzsche, F. Über Wahrheit und Lüge im aussermoralischen Sinn. In Werke in drei Bänden. B.3. Múnchen: Carl Hansen, 1973. 
um acesso, embora ele mesmo seja acessso enquanto, por um lado, é instrumento. O verbo deveria servir para falar da hipóstase do verbo. Deus era, assim, um problema de linguagem: a questão seria falar e não se falar sobre ele, e como. Mais que isso: Deus era linguagem, e a tarefa humana seria encontrar outra linguagem capaz de traduzi-lo, capaz de falar sobre ele mesmo que limitadamente. Porque Deus se apresenta como linguagem, Deus é linguagem, mas ela não sendo Deus, é a vontade de tocá-lo. Daí toda a linguagem se instaurar como um ato religioso, como contato, como conversão. (Talvez aí se encontre a explicação para a aura existente em torno da filosofia da linguagem e outras esferas de estudo referidas à linguagem; conseqüentemente, da própria hermenêutica. Porque a linguagem é, sobretudo, um símbolo da humanidade, que é justamente o que aproxima o animal-homem de Deus e carrega em si a esperança de conhecê-lo.).

Por isso - não seria puro acaso - a hermenêutica manifesta historicamente sua afinidade com a religiosidade, ao brotar em primeira mão da interpretação de textos que são religiosos; ela é, de certo modo, a secularização da exegese bíblica - cuja origem está na tradução de textos sagrados - que intenta alcançar a mensagem sagrada trazendo-a para a limitada compreensão humana. Originalmente, no entanto, o próprio mundo é que é um texto a ser decifrado, e é, para o homem primitivo ou para o simplesmente perplexo, um texto tanto mais sagrado quanto mais complexo, e menos evidente quanto mais cru de explicações. Assim, o caráter religioso da hermenêutica aparece, como que por atavismo, na forma da atitude interpretativa mais simples, voltada para o que mesmo deixou há muito de ser ou sequer aproxima-se do sagrado (ao menos explicitamente). A atitude hermenêutica inicia-se, de qualquer modo, com este deparar-se com 0 estranho, cuja sacralidade reside no seu ser primitivo para o conhecimento, ele é o não conhecido que preside o real mesmo quando todo conhecimento racional $\mathrm{e}$ elucidativo parece ter se implantado, quando se desvendou o mundo; ele é o que sobra, como uma sombra de contomos indefiníveis depois que toda clareza do entendimento lançou-se sobre o mundo. Por isso a atitude hermenêutica, por excelência, é, em seu imo, exegética, pois no seio da cultura a palavra é o elo de ligação com todo o estranho, e, enquanto palavra sagrada, ela é o dito maior, verdade revelada cujo conhecimento fora por longo tempo o objetivo de toda investigação.

Esta palavra, ao final (apresente-se ela como sagrada ou profana - a diferença de uma e outra reside no grau de estranheza que ela procura encontrar), de cujo mistério se extrai a necessidade de interpretar, é a própria concessão do estranho, ou seja, possibilidade que se abre apenas no outro, através dele, constituindo um potencial que não pode ser arrancado a outro lugar. A palavra, sem dúvida, é um ato do sujeito, mas nasce pela ordem criada inintencionalmente pelo objeto. Ela é uma forma de expressar o objeto, se ele não existe, do mesmo modo não há palavra. É isso que significa dizer que ela é expressão do sujeito surgida no choque com a coisa, ela é também apelo da coisa ao sujeito, e não apenas sua intenção. A hermenêutica aí é a forma teórica privilegiada para a racionalidade e a compreensão humanas depararem-se com o outro (o imponderavelmente estranho, 
de outra ordem, inacessivel), atitude que é o próprio sentido da aventura do pensamento $^{3}$ (sem o qual não há mundo), que caracteriza o papel próprio da hermenêutica: a escuta que dará chance à fala. Assim é que a hermenêutica enquanto abertura - quer ouvir a voz do que não tem voz e não simplesmente ser sua tradução ou uma fala sobre - se fosse assim ela aproximar-se-ia do procedimento explicativo que ela quer criticar essencialmente.

A linguagem será a ponte entre dois mundos que diz ao ser humano o seu próprio modo de existência, que o faz ser o que é historicamente, sem o que the restaria ser, talvez, apenas animal em meio à natureza. A linguagem desde sempre - e Aristóteles viu bem isto - é o que separa o ser humano do ser animal, tomando o homem humano porque possuidor de lógos; ela é, neste tempo, o que institui a esquizofrenia frente ao estranho, separando-o deste estranho, dando ao ser humano, noutra via, um elo com o mundo, dando-lhe a ficção que ele é, paradoxalmente, o que é a sua verdade, a história, a cultura. Através da linguagem, então, o homem se separa da natureza, enquanto, por outro ângulo de abordagem, encontra uma espécie de nostalgia da natureza - o que ele deixou para trás - sem a qual ele também estaria perdido, pois saber o que se é, é saber também o que não se é mais. Em outras palavras, ao falar da natureza para entrar (enquanto tenta alcançar uma forma de dizer e compreender a realidade imediata) e fugir dela (enquanto tenta criar um mundo a parte), o homem construiu-se como cultura, que é o mundo dos seus símbolos, que é a sua linguagem. Por outras palavras, na sua tentativa de abordar o estranho, a aventura lingüística do homem fundou a si mesma como um mundo cindido em relação à imediatidade simples.

A linguagem é o que o ser humano inventa, porta que ele abre, porta por onde ele sai, a capacitadora do mundo possível, hábitat natural dos humanos, onde se está em casa e onde se encontra o limite fundamental na impossibilidade de aportar definitivamente naquele outro estranho que o ser humano deseja e que, por vezes, o atormenta. A linguagem tem a pretensão de torná-lo cada vez mais próximo, assim como quer ser a expressão de tudo. Ela quer dizer, abrir, cortando o outro ao meio, dilacerando-o, se necessário, para concretizar seu desiderato essencial. Ela será, portanto, esse corte, clivagem na realidade, não mera navalha que serve de instrumento no ato de desvendar o real, pois ela é o modo de se estar dentro do real no qual ela mesma se torna enquanto rompe e esfacela a imediatidade e, por isso, quando estamos nela não somos mais apenas bichos. Ela é a fenda aberta na mera imediatidade, ela é um buraco no sensível, sem o que ele estaria fechado para a condição humana.

Este é o conceito de hermenêutica de Gadamer: "teoria da experiência real que é o pensar". Op. cit., p. 19. 
Porque aquele algo, aquele estranho, lhe escapa, a hermenêutica precisa reconhecer a necessidade de andar pelas vias estreitas dos seus limites. Então, ela acaba por oscilar entre a sua pretensão de universalidade, de ver o todo como interpretável, e o limite que estanca toda pretensão: mas ela não terá sentido sem tal pretensão. Assim, é que se poderá compreender por que, segundo Gadamer, "ser que pode ser compreendido é linguagem", porque, implicitamente, apenas até onde possa haver linguagem a compreensão existe (o contrário, entretanto, não é verdadeiro), e tudo que é humano pode ser linguagem. Se existe um fora da linguagem a hermenêutica na sua forma secularizada não se ocupará dele, por isso ela será antimetafísica e antiteológica. Por outro lado, será metafísica enquanto absolutiza a linguagem por ser incapaz de conceber como o humano se poderia dar fora dela. Fora há apenas a interdição. Assim é que a hermenêutica não buscará mais o sagrado pleno, mas apenas o estranho, que é uma forma de apresentação do religioso, porém sob a forma secularizada do que ainda não se conhece. A hermenêutica moderna é esta secularização cujo limite paradoxal é a pretensão de universalidade. Ela não pode, deste modo, pensar simplesmente que tudo é linguagem, porque existe o incompreensivel, o intangivel para a razão e as várias formas de linguagem, sendo deste intangivel que ela toma o seu impulso, 0 seu limite e a pretensão de não obedecer a um tal limite. Em outras palavras, a interpretação nasce na necessidade e no desejo de tornar acessivel o inacessivel, mesmo que se trate de utopia. (Daí poder pensar-se que o verbo é a não linguagem dentro da linguagem. A linguagem que ninguém pode compreender, como que uma fala absoluta.).

A linguagem é o modo de ser do mundo humano separado do mundo dos deuses que a hermenêutica, após sua reviravolta dessacralizada quer compreender num novo sentido, sendo, também, o guardador do desejo de transcender 0 humano e alcançar este outro que se the põe como promessa enquanto aparece sob o estigma do limite que parece existir para ser transposto, a partir do qual se coloca toda pergunta possível. A pergunta - que é o nó da hermenêutica - nasce no limite: o que há do outro lado, por que estou aquém e como posso transpor o limite? A hermenêutica tem de ser uma forma de conhecimento que opta pela experiência do limite do conhecimento, que é o próprio limite da linguagem humana, o limite da tradição e do pré-conceito, da história efetual ou continuum (Wirkungsgeschichte) do qual fala Gadamer, numa palavra, o limite da interpretação e da compreensão. O seu avanço tem sua importância aí, no fato de buscar esclarecer a esta história - que é a própria tradição - valorizando seus dogmas ou verdades pré-concebidas na contramão deles mesmos, por encará-los como história sedimentada, como experiência que constitui o ser humano presente. A verdade - é de se pensar nela neste momento - não será

Jones, Douglas. Defusing Gadamer's horizons. Premisse. v. 2, n. 8, Set. 27, 1995, p. 4. "Gadamer's overarching project is a very nest instance of the ancient non-Christian effort to silence the culturally transcendent voice of God, exiling it behind an unreachable horizon, far beyond our opaque veil of language". 
transcendental, mas histórica e, por conseguinte, lingüística, porque o humano não acontece sem a linguagem. Ela mesma sustenta-se na história. Sem ela o ser humano seria uma empresa frustrada ou nem sequer seria, posto que só se pode pensar o humano e conceber-se como tal na medida da condição que é a linguagem.

A dimensão lingǘstica do conhecimento humano é uma colocação já posta por Schleiermacher: "a linguagem é o meio universal no qual se realiza a compreensão mesma". Ele, inicialmente preocupado com a interpretação no contexto teológico, passou a considerar a hermenêutica a arte da compreensão (Kunst des Verstehens) dirigida à interpretação de textos falados ou escritos. Para ele, a hermenêutica se constitui na reconstrução histórica e divinatória, objetiva e subjetiva de um dado discurso, necessitando para tanto que o intérprete se aprofunde na intenção do autor do texto, na sua vivência, na situação histórica. ${ }^{6}$ A compreensão será, para Schleiermacher, uma atividade análoga à fala, derivada da lingüisticidade ou capacidade do discurso (Sprachfähigkeit), isto é, seu conhecimento da língua (Sprache) e seu domínio da fala (Rede). Em Schleiemacher "o falar (Das Reden) é o meio para a comunidade (Gemeinschaftlichkeit) do pensar"." O conhecimento será compartido e construido nesta relação. "Schleiermacher pensava que todo ser humano era equipado com uma disposição lingüística básica, que era realizada pela obtenção de uma linguagem dada num momento particular de sua história e pela internalização de suas regras gramaticais. Linguagem e gramática constituiam uma unidade indissolúvel produtora de conhecimento que era resultado, deste modo, do sistema lingüístico pessoal diretamente relacionado ao impessoal". ${ }^{8}$ Aí ele já apontava para a idéia de círculo hermenêutico. Dentro da lingüisticidade, para Schleiermacher, a compreensão (Verstehen) e a interpretação (Auslegung) andam juntas. Ambas ocorrem quando qualquer possibilidade de mal-entendidos se avizinham. Schleiermacher preocupar-se-á com a relação entre indivíduo e todo, com a situação do sujeito e sua intenção como demonstração do lugar que ele ocupa no ato da compreensão.

Gadamer, por sua vez, andará ao contrário: para ele compreender é pôr-se de acordo com a coisa, e não simplesmente no lugar do outro para reproduzir suas vivências. Mais do que a intenção vale o condicionamento histórico da posição pessoal do autor e a história efetual do que ele produziu, o que dá ao texto uma independência em relação ao seu produtor. $O$ texto, o que deveria ser conhecido,

- Gadamer, H. G. Op. cit., p. 467.

- A intenção era um problema já posto por outros pensadores anteriormente a Schleiermacher, é o caso de C. Wolff e outro téorico do Esclarecimento Chladenius. Ver Müller-Vollmer, Kurt. The Hermeneutics Reader. New York: Continuum, 1988. p. 1-8.

7 Schleiermacher, Friedrich. Hermeneutik und Kritik. Frankfurt (M): Suhrkamp, 1993. p. 76.

Müller-Vollmer, Kurt. Op. cit., p. 10. 
adquire dignidade. Ele não é o que alguém põe nele, nem o que simplesmente nele alguém é capaz de ler. Algo continua sobrando, assim como algo fica de fora quando a questão é a leitura do texto do mundo, pois a compreensão nunca é absoluta, antes é condicionada historicamente, assim como o é o sujeito.

Diferentemente de Schleiermacher, Gadamer não distinguirá as esferas dentro da própria linguagem, entendendo-a como uma variedade de significados onde. contradições e ambigüidades convivem dentro da mesma palavra. A linguagem será mais do que uma capacidade humana, será a expressão do fato de que o homem tem um mundo e sua verdadeira existência reside nesta possibilidade. E o mundo não será simplesmente o entorno no qual a liberdade não acedeu, ele é a transcendência deste entorno, do mero meio ambiente ao qual o homem primitivo ou o animal se mimetizariam.

No desvendamento da verdade a pergunta será a âncora do homem neste abismo existente entre o seu mundo e o mundo do desconhecido, ela será o modo pelo qual se instaura a consciência hermenêutica sempre aberta para o estranho. Esta consciência hermenêutica vê o mundo através de uma mediação que não o é meramente da razão e através da qual tudo pode desdobrar-se em sentido, mesmo o que parece impossível. Um tal sentido é sempre construído a partir de algo que a hermenêutica considera o sentido prévio instaurado sob a forma da linguagem $e$ a sua história. O que significa um tal sentido é fundamental para a compreensão da hermenêutica, caso contrário seria de se pensar a inexistência de uma falta de sentido. O sentido nem sempre se refere a uma proposição ou evento particular em termos absolutos, mas é sempre uma determinada conexão com a história da coisa particular, ele diz respeito a uma relação do particular com o todo. Destarte, mesmo o nonsense do particular (da arte ou dos eventos históricos absurdos) adquire sentido frente à história, pois não se trata de um sentido enquanto razão por oposição à loucura, e sim enquanto lugar dentro do qual as coisas podem ser compreendidas, embora, muitas vezes, não sejam justificáveis. O sem sentido, assim, tem sentido (embora não tenha) basta distinguir em relação a quê.

A pergunta que não surge no vazio só pode nascer aí. Contudo, ela representa, enquanto abertura, um certo vazio, espaço que nem sempre será preenchido, uma instabilidade ou sensação de se estar perdido que impulsiona para o conhecimento, que faz os ouvidos ficarem atentos em busca de sinais. Sem esta abertura que ela é dentro de um limite, o homem sucumbiria ao seus dogmas se antes já não estivesse preso às teias de uma autoconsciência idealista que teria engolido sua própria chance de experienciar o mundo e, assim, viver a sua plena aventura e saber. Esta abertura - que implica também o sentido da aventura para o que se apresenta como outro, dá o conceito hermenêutico de experiência sintetizado por Gadamer: a abertura que caracteriza a essência da experiência é, 
falando logicamente esta abertura do "assim ou de outro modo", ou seja, conhecimento que passou pela pergunta de que algo possa ser o que não parece ser e que não seja o que poderia ter sido. Então, o sentido e o significado estão abertos, alocam-se no possivel, e não no necessário. A experiência hermenêutica acontece como pergunta ao outro e se concretiza na resposta sem hipostasiação da certeza, por isso não há a busca por uma objetividade no sentido de algo alcançavel por um método.

Em suma, a hermenêutica quer dizer que o modo como o ser humano se abre para o mundo é o da pergunta, e aquele que pergunta quer ouvir. Ela é a forma da experiência hermenêutica que, na seqüência, se apresenta como experiência negativa ao modo da dialética platônica; a pergunta é saber verdadeiro em relação a uma resposta cuja pretensão nem sempre alcança a complexidade do perguntar. Investigar o que é podendo ser de outro modo culmina na aporia socrática: saber que não se sabe. Por isso perguntar é de certo modo romper, quebrar aquilo sobre o que se pergunta, não aceitar que nele esteja desde sempre a própria resposta; a única resposta autêntica seria aquela que nasce depois desta quebra, que abraça este ser desmontado e o desenvolve sob a sua nova condição. A resposta, para Gadamer, segue o sentido da pergunta, não é algo que o contradiga, porém não é algo que estava simplesmente pronto tendo que nascer no seio da experiência. Por isso a pergunta não é em si resposta, embora toda resposta se dê no sentido da pergunta.

A pergunta é a manifestação da experiência do estranhamento, que implica distanciamento. Toda experiência o é do estranho. Como corolário desta idéia pode se dizer que não haveria hermenêutica sem a existência da distância, que existe porque há um outro antes do qual há este vazio a impedir o seu alcance. Esta distância diz o tempo todo que ele não pode ser simplesmente tomado, que experimentá-lo não é engoli-lo, tomá-lo como um objeto à manipulação. Experimentá-lo é estar aberto ao que ele apresenta como possivel, é entregar-se à sua verdade.

$\mathrm{Da}$ natureza da hermenêutica é instaurar-se neste abismo entre duas realidades que se expõem sob a forma da relação entre o mesmo e o estranho, 0 sujeito e objeto, na qual não há hierarquia gnosiológica, posto que o sujeito não é o todo-poderoso doador de sentido ao objeto, que adquire um estatuto e uma verdade próprios, garantidos sob um sentido histórico. Este distanciamento que pode tanto ser espacial quanto temporal é um elemento fundamental da experiência hermenêutica, sem ele não há compreensão ou interpretação que se possam ter como verdadeiras (mas donde emana a sua verdade?). Falar em uma verdade da interpretação implica a condição que tem o sujeito de não definir simplesmente o objeto. Interpretar é a experiência de um "afastar-se aproximando-se": apenas aí uma verdade toma sentido. Como condição necessária um tal distanciamento mostra que se a coisa está na consciência ou se

Gadamer, H-G. Op. cit., p. 139. 
esta dela se apoderou, não será possível, então, olhá-la hermeneuticamente. Um olhar hermenêutico é aquele que se constrói na distância como forma de respeito à condição da alteridade. Ele é anti-inquisitorial. Ele mesmo já é fruto do desenvolvimento da história desta distância ou da própria história de uma separação e, num sentido dialético, esta separação é o desejo de estar junto, o que não significa eliminar a distância, mesmo porque ela é ineliminável. (Esta distância, contudo, fora vista como o que deveria ser eliminado). Contrariamente a Schleiermacher, Droysen e tantos outros que "concebiam a compreensão como um meio de superação da distância histórica entre o intérprete e o fenômeno histórico, Gadamer mantém a natureza histórica do fenômeno mesmo", ${ }^{10}$ o que equivale a manter a distância e infiltrar-se nela, intrometendo-se-lhe sem aniquilála por meio de uma negação abstrata. A distância permanece e se torna concreta na experiência da história que penetra no indivíduo e não pode ser a ele reduzida, assim, ambos relacionam-se sem uma fusão absoluta.

A compreensão também é a experiência que o sujeito faz consigo mesmo em relação ao objeto, ela cresce naquele abismo entre o eu e o que não é eu. Ela é o nome da experiência hermenêutica que consiste no deixar-se sensibilizar pelo outro, no se deixar tomar pela alteridade no momento da sua leitura. Leitura que é o ato de cavar a verdade da coisa antes da imposição de uma verdade do sujeito que venha a ocultá-la. Ela é esta permissão da fala da alteridade, é o abandono no estranhamento que provoca no sujeito um certo esquecimento de sua própria condição de sujeito que teria no texto que se lhe apresenta um mero pretexto para a sua própria fala. Necessariamente, para chegar a tal atitude, a consciência hermenêutica é aquela que reconhece os seus próprios pré-conceitos (Vorurteilen) e busca no outro o esclarecimento do seu próprio horizonte que se forma a partir deles. Todo sujeito é o conjunto destes pré-conceitos que formarão o horizonte de compreensão a partir do qual ele lê o mundo. Inevitáveis e necessários, tais préjuízos e pré-conceitos têm, por um lado, a potência de ensurdecer o sujeito para toda voz a ele externa, a voz da alteridade, cuja expressão ele deveria promover; por outro lado, são condição da emancipação daquela voz, a via pela qual a expressão terá que passar. Sujeito, em resumo, antes de ser atividade, é aquele que ouve.

Deste modo é que a experiência hermenêutica é a chance para o mútuo esclarecimento entre o horizonte do sujeito e do objeto, e se promove no ato quase que autonegativo por parte do sujeito de refutar os próprios pré-conceitos que o formam. Eis um elemento crítico da hermenêutica. Portanto, na experiência autêntica o sujeito sabe da determinação histónica na qual ele está desde sempre inserido. Este caráter histórico da experiência leva o sujeito à experiência de sua própria finitude e de seus condicionamentos, à compreensão de que ele não é uma

${ }^{10}$ Müller-Vollmer, Kurt. Op. cit., p. 38. 
verdade absoluta. Leva também ao contato com o caráter único dos acontecimentos da vida, à relação com o particular. Neste sentido a experiência é vivência (Erlebniss). Uma experiência é alguma coisa irrepetivel (difere do experimento científico, que pode ser repetido e controlado, em princípio, ad infinitum) que pode ser contradita por outra. Cada uma é um choque que pode ser reavaliado, corrigido, com o avanço das seguintes. Este é o seu elemento dialético exposto sob a forma da negação determinada hegeliana. Então, o caráter da pergunta a ela inerente existe aí, nesta abertura na qual não há resposta préfixada, quando respeita o sentido, a orientação do processo no qual todo evento, embora único, nasce pela negação do antecedente e aponta para outro que virá a negá-lo. Neste processo é constituído o sentido como ato de sedimentação da verdade produzida na história que se dá a conhecer através do jogo dialético do guardar e superar extraído de Hegel.

A compreensão é esta abertura na qual ocorre a fusão de horizontes do sujeito e do objeto ou do texto e de seu intérprete-condicionada na história. A historicidade é decisiva na experiência hermenêutica, ela se dá na forma da tradição composta por pré-conceitos que compõem o arcabouço sobre o qual a realidade do indivíduo se instaura. Enquanto sentido prévio ou pré-compreensão, a tradição é algo que diz muito mais do que o que possa simplesmente ser elaborado no presente, o que, aliás, seria impossível, pois mesmo os juízos presentes se elaboram a partir de um substrato histónico. Gadamer recobrará um sentido construtivo e positivo para o pré-conceito lembrando Bacon, que se teria referido a eles na figura dos Idola que condicionam a mente humana obnubilando, senão impedindo, todo saber melhor, aquele que avança rumo à maioridade humana, livrando o ser humano do obscurantismo ao qual, pensava-se, ele estivera preso por longa data. A esta conotação pejorativa sustentada no Iluminismo - e que será um dos seus legados à posteridade - que pensava os préconceitos como submissão à autoridade - ideal defendido na Idade Média - a qual deveria ser substituída pela coragem do intelecto, (aquela mesma maioridade à qual apela Kant no seu "Was ist Aufklärung?"), Gadamer sustenta o caráter verdadeiro dos pré-conceitos, retomando a reflexão dos românticos que propugnava uma crítica ao Iluminismo defendendo o valor e a verdade da tradição. Contudo, Gadamer defenderá, contra os próprios românticos, o valor e a verdade da tradição da razão que eles, de certo modo, gostariam de ver por terra. Gadamer reunirá a tradição e a razão retirando de circuito os mal-entendidos que cercaram a disputa de lugar na qual elas se viram envolvidas. Ele mostrará que a posição iluminista avessa à tradição é também um pré-conceito historicamente fundado ao qual a compreensão aporta desvendando o seu sentido. A tradição será um momento da liberdade no qual o mundo humano é conservado e cultivado. É algo que se não pode negar porque tal negação consistiria em negar a própria verdade humana, aquilo que o ser humano é, a história e seu desdobramento no presente, 
seria negar o que aconteceu. A verdade dada na tradição não é dogmática, simplesmente, mas diz respeito à impossibilidade de se apagar o que aconteceu e à conseqüência inevitável de que o ser humano é contituído por isso. ${ }^{11}$ Esta é a "consciência crítica"12 típica da hermenêutica.

A partir disto se vê que o problema hermenêutico não existe apenas em função de uma problematização acerca do método para o alcance da verdade. $\mathrm{Na}$ obra Verdade e Método de Gadamer, buscar-se-á um entendimento sobre a compreensão, o que ela seja e o que se produz quando ela ocorre. Muito antes de entregar-se à fundação de uma metodologia, seu projeto opta pelo rastreamento da experiência da verdade. $O$ texto não é um método para encontrá-la, pois entre verdade e método há um desencontro que anula aquela tentativa. Um desencontro que se mostra no conceito de experiência presente na hermenêutica, o qual implica, por sua vez, como já se viu, renovação, encontro com o inesperado, o choque como constitutivo do processo de compreensão. Método, por sua vez, é algo dado de antemão, que não comporta nenhum destes elementos, ele não assume um deslumbrar-se com a verdade, pois, ao contrário de abrir-se para o mundo, ele pressupõe a tomada do mundo ou de tudo que apareça como estranho e sua posterior experimentação num nível cuja pretensão é a da pura objetividade. Ele é fechado e tenta em seu interior delimitar o mundo, constrangendo-o, classificando-o. Neste sentido, o método é objetivista, embora, seja, por outro lado, idealista enquanto concebido a priori. A compreensão, por sua vez, vê na experiência a saída do cubículo da consciência idealista. O método vê a experiência como experimento manipulatório de uma alteridade que ele apenas pode pensar como objeto para si, permanecendo naquele cubículo.

Enquanto a compreensão é experiência na qual o sujeito se envolve e modifica a si mesmo, o puro método é o experimento em que o sujeito não quer se envolver, que não o afetará justamente porque o sujeito se põe como absoluto. Daí a famosa distinção proposta por W. Dilthey entre o procedimento das ciências chamadas da natureza e as chamadas ciências do espirito ou humanas ser retomada por Gadamer. Na primeira, vingaria a explicação, ou a subtilitas explicandi (erklären) como forma de fazer regredir causalmente um fenômeno particular às regras gerais. Na segunda, a compreensão ou subtilitas intelligendi (Verstehen), a apreensão de sentido é considerada para além da explicação causal. $\mathrm{Na}$ primeira, o ideal da objetividade exclui ficticiamente um envolvimento do sujeito pretensamente imperturbável em sua tarefa de investição do mundo, enquanto na segunda é preciso verificar o lugar do sujeito no processo buscando o

\footnotetext{
"Ver Lang, Peter C. Hermeneutik, Ideologiekritik, Ästhetik. Über Gadamer und Adomo sowie Fragen eine aktuellen Ästhetik. Königstein: Äthenäum, Hain, Scriptor, Hanstein, 1981. p. 20-21. O autor defende a idéia de uma fundamentação dogmática para a verdade com base na estética e também na tradição na teoria de Gadamer.

12 Gadamer, H. G. Op. cit., p. 27.
} 
seu próprio auto-esclarecimento. Mas a antítese entre verdade e método não quer significar que o procedimento métodico deva ser excluído da busca pela verdade no âmbito do conhecimento, trata-se, antes, de expor as relações recíprocas que existem entre uma ciência metódica e uma verdade original que transcende 0 métodico. ${ }^{13}$ Gadamer apenas quererá dar prioridade ao mundo da vida como abertura sem deixar de levar em conta as limitações do procedimento metódico ao qual a hermenêutica é necessária como reflexão crítica.

Então, não devendo abandonar a ciência e o método, Gadamer buscará a arte como lugar de uma verdade legítima, por ser um elemento onde se dá a abertura tão necessária à experiência hermenêutica. A experiência estética é o modelo da compreensão, pois possui em si um desregramento, uma posição da subjetividade disposta a entregar-se à alteridade da coisa que a ciência não alcança no seu proceder fechado. A arte como lugar de uma verdade fundamental apontará na sua estranheza o necessário questionamento sobre o lugar do sujeito, o que não significará dizer que o processo hermenêutico seja simplesmente subjetivo. A arte dirá, no seu silêncio eloqüente o estatuto radical do objeto que obriga a repensar a posição do sujeito.

A posição do sujeito é fundamental na medida em que é ele que institui a pergunta, sem a qual nada aconteceria. A sua posição enquanto algo apartado do objeto em função daquele estranhamento (Verfremdung) que apenas ele pode ter coloca a necessidade de desvendar o seu estatuto. Sujeito é aquilo que se constitui na experiência que se coagula na forma da tradição. Ele é ativo e passivo, nascendo em contato com o que não é ele e que ele desejará desvendar como forma, inclusive, de desvendar a si mesmo. O sujeito é o intérprete que vê no texto regras próprias de estruturação com as quais ele deverá contracenar e as quais ele não deverá manipular. Ele será responsável pela criação de um sentido para o texto, atividade que seria impossivel sem o seu intercurso; porém esta criação não é um ato arbitrário, nem meramente deliberado, ela acontecerá de forma autêntica, se for considerado no texto o elemento estranho que dá ao próprio texto a sua dignidade e o torna um não sujeito, diferenciando assim as duas instâncias envolvidas no processo, fazendo com que o sujeito perceba a si mesmo como outro de alguma coisa, e neste sentido também objeto, o que se constitui por ele e não é mais autocriado, causa sui. Tal criação se dá no mesmo sentido da criação na arte, ou seja, sempre vai além da intenção do autor.

Schleiemacher, interessado na perspectiva do sujeito, perguntava pelas condições de possibilidade do conhecimento deste estranho, em outras palavras, pelas condições de possibilidade da compreensão destituindo a razão do lugar nobre de decisão sobre a verdade, deixando tal lugar à linguagem. Dito em poucas palavras, antes do sujeito ser razão ele será linguagem. E a significação mais

13 Bubner. Rüdiger. La filosofia alemana contemporanea. Madri: Cátedra, 1991. p. 72. 
originária da linguagem será sentido que não pode ser definido com base nos pressupostos da razão, pois indica muito mais o conteúdo de uma compreensão possível do que algo subsumível a regras ou simplesmente sistematizável. Afirmar que a razão não é a instância maior a julgar e definir o mundo significa diminuir o valor do sujeito transcendental, o sujeito idealista que se instaura como racionalidade insuspeita, que na sua forma empíica veria no texto apenas o que lhe é dado pelo sujeito. A razão que não justifica racionalmente seu lugar como instância legitimadora do sentido estará submetida à linguagem, agora instância intransponivel. A linguagem será compreendida como algo histórico e a posição do sujeito autônomo absoluto garantida pelo idealismo é agora justamente colocada em xeque em função de sua inserção no processo histórico sob condições por ele não dominadas. A linguagem é este horizonte não dominado, pré-existente, sob cuja autonomia o sujeito está delimitado.

Tal concepção é afim à noção de círculo hermenêutico dada em Heidegger, enquanto a pré-estrutura da compreensão, que se traduz na compreensão do Dasein, o estar-aí ao qual ninguém pode escapar, pois constitui a condição intransponível para o ser humano a partir da qual ele existe. Como se a própria possibilidade de perguntar já tivesse como base a pergunta anterior sobre aquele que quer compreender. Aquele que quer compreender está desde sempre inserido num horizonte de compreensão maior que forma o seu horizonte particular. Este horizonte prévio é a linguagem à qual o ser humano pertence, dentro da qual ele instaura um projeto inicial de sentido que se desdobra ao infinito. $O$ trabalho hermenêutico é o renovar incessante deste projeto que tem como base a atividade do sujeito que pergunta, sugerindo interpretações que são esboços de sentido renováveis e subsumíveis a outros que o provam ou desaprovam. A compreensão só é instaurada após provar-se a legitimidade de pré-suposições que constam do projeto.

Heidegger falava numa história do ser, Gadamer substituirá a história do ser pela da efetuação. A verdade será um acontecer efetivo-histórico dentro do qual o homem está e ao qual se manifesta um sentido. A verdade toda nunca é apreendida porque seria impossível uma posse absoluta do que se passou. Um tanto quanto inalcançável, ela será, no seu acesso possível, a forma como se chega à história no maior grau de proximidade possivel aos seus conteúdos que se tornam autônomos em relação à consciência humana, e com os quais a consciência hermenêutica quer novamente comunicar-se. "A compreensão é histórica na medida em que está condicionada pela interpretação de efetivação histónica do passado, pois ela entra constitutivamente na realização de nossa própria compreensão" ${ }^{14} \mathrm{Na}$ realização da compreensão não importa um passado que se nos apresenta de um modo direto, o que seria falso; o que importa é a

14 Coreth, Emerich. Questões fundamentais de hermenêutica. São Paulo: EPU, 1973. p. 127. 
forma como ele foi recebido no presente e o que ele provocou. Então é preciso analisar.o seu caminho, a via pela qual cada evento se transformou ao longo de sua existência que é a história. Serão definidos aí os conceitos de compreensão e interpretação a partir da reconstrução do passado. Assim "compreender se dará na imediatez da visão da inteligência que apreende um sentido e interpretar na mediação pelo conhecimento racional que pressupõe a imediatez da compreensão prévia, mediando-a, porém, racionalmente por decomposição, fundamentação e explicação, elevando-a, assim, à imediatez mediata de uma compreensão aprofundada e expressamente desenvolvida"15. Compreender não será inteiro sem interpretar, interpretar não será possivel sem compreender. Isto é o conhecimento que a hermenêutica promove como verdadeiro, no qual o universal, o reino da cultura, da história, da tradição, e o reino do individual, os homens particulares, o sujeito empírico e a vida concreta, nos seus acontecimentos múltiplos, encontram seu sentido e dignidade, sem alternativas realistas ou idealistas. A hermenêutica quer, no atual estado de uma história à qual ela mesma está submetida, promover esta reflexão crítica sobre o mundo passado e o mundo presente.

No processo hermenêutico a linguagem nasce do outro. Todo o processo de conhecimento, por uma ou outra via, nasce do outro. Ele é tudo o que não é sujeito e, portanto, é objeto enquanto aquilo que, segundo palavras de Adorno, é "incansavelmente proposto". A importância da alteridade no processo do conhecimento diz a possibilidade de se compreender onde começa a verdade neste âmbito, e impõe uma relação que é ética no seio do elemento que parece em primeira vista puramente gnosiológico.

A linguagem que diz o que é o ser humano é algo instaurado a partir do outro. O ser humano é fruto de sua insatisfação com tal espécie de alienação. Ele é o desejo de, rompendo esta condição, chegar ao que ele não é. Ele é heterônomo de maneira ancestralmente fundada, o que implica um modo particular de relacionar-se com este outro, podendo temê-lo e, assim, optar pela autodefesa ou acolhê-lo, optando pela experiência do estranho como forma de avançar no conhecimento. A linguagem pode ser a acolhida.

${ }^{15}$ Coreth, E. Op. cit., p. 48. 